STUDI

FRANCESI

\section{Studi Francesi}

Rivista quadrimestrale fondata da Franco Simone

170 (LVII | II) | 2013

Varia

\title{
Aimé du Mont-Cassin, Ystoire de li Normant. Édition par Michèle Guéret-Laferté
}

\section{Maria Colombo Timelli}

\section{(2) OpenEdition}

1 Journals

\section{Édition électronique}

URL : https://journals.openedition.org/studifrancesi/3002

DOI : 10.4000/studifrancesi.3002

ISSN : 2421-5856

Éditeur

Rosenberg \& Sellier

\section{Édition imprimée}

Date de publication : 1 juillet 2013

Pagination : 430-431

ISSN : 0039-2944

\section{Référence électronique}

Maria Colombo Timelli, « Aimé du Mont-Cassin, Ystoire de li Normant. Édition par Michèle Guéret-

Laferté », Studi Francesi [En ligne], 170 (LVII | II) | 2013, mis en ligne le 30 novembre 2015, consulté le 02 février 2023. URL : http://journals.openedition.org/studifrancesi/3002 ; DOI : https://doi.org/ 10.4000/studifrancesi.3002

Ce document a été généré automatiquement le 2 février 2023.

\section{(c) () $\odot$}

Creative Commons - Attribution - Pas d'Utilisation Commerciale - Pas de Modification 4.0 International - CC BY-NC-ND 4.0

https://creativecommons.org/licenses/by-nc-nd/4.0/ 


\title{
Aimé du Mont-Cassin, Ystoire de li Normant. Édition par Michèle Guéret-Laferté
}

\author{
Maria Colombo Timelli
}

\section{RÉFÉRENCE}

Aimé du Mont-Cassin, Ystoire de li Normant. Édition du manuscrit BnF fr. 688 par Michèle GUÉRET-LAFERTÉ, Paris, Honoré Champion, 2011 («CFMA», 166), pp. 688.

1 L'Historia Normannorum, rédigée vers 1080 par Aimé de Mont-Cassin, ne nous est connue que sous la forme d'une traduction française du début du XIv esiècle, l'Ystoire de li Normant, conservée dans un manuscrit unique (Paris, BnF, fr. 688). Michèle GuéretLaferté en fournit ici une nouvelle édition - après celles de J.-J. Champollion-Figeac (1835) et de V. de Bartholomaeis (1935) - qui se signale par son érudition et son achèvement.

2 L'introduction, particulièrement dense, offre au lecteur toutes les informations utiles pour aborder un texte complexe tant par son contenu que par sa forme. Les aspects historiques, culturels et littéraires font l'objet des trois premiers chapitres. L'éditrice connaît bien le cadre politique de l'Italie méridionale du xi siècle et le présente très clairement (pp. 16-28); suivent quelques pages consacrées à Aimé de Mont-Cassin, dont la biographie et l'œuvre sont assez bien connues (pp. 28-36), puis une étude serrée de la version française: l'éditrice analyse avec une grande finesse les interventions du traducteur anonyme, qui prennent la forme de commentaires, gloses, prises de parole diverses, voire critiques du texte-source (pp. 36-63). La conception de l'histoire d'Aimé fait l'objet d'un examen approfondi (pp. 64-153), prenant en compte le contenu, l'organisation de la matière, sans oublier les aspects formels. Si la période objet de l'Historia couvre un peu moins de quatre-vingts ans, la complexité des événements relatés est telle qu'une simple présentation chronologique ne suffirait certainement 
pas; l'éditrice relève en effet quelques structures fondamentales sur lesquelles Aimé a fondé son écriture: les parallélismes entre Richard et Robert Guiscard, des oppositions et des antithèses - qui se réduisent au fond à la lutte entre le Bien et le Mal -, des échos, des reprises, des symétries entre les différents livres et chapitres qui structurent l'ouvrage. Quant au rapport entre «récit» et «histoire», M.G.-L. souligne quelques points saillants: les indications temporelles, rares dans le texte; le portrait qu'Aimé offre des Normands, vaillants, aidés par Dieu, guidés par de grands stratèges. D'autre part, Aimé ne renonce pas à raconter quelques scènes alertes, introduire une anecdote, enchâsser des discours; son écriture est aussi marquée par les citations bibliques et les prophéties, ce qui correspond à une vision du monde et de l'histoire qui transcende les réalités humaines, mais aussi par un emploi habile du langage figuré, des métaphores, parfois de l'ironie.

3 La langue composite de l'Ystoire de li Normant exige des compétences vastes, allant du latin à l'ancien français à l'«italien» médiéval; M.G.-L. jongle aisément d'une langue à l'autre, ce qui lui permet de comprendre, de justifier et, le cas échéant, d'expliquer des formes qui paraîtraient aberrantes à moins expert qu'elle. Un autre mérite du chapitre qu'elle consacre à la langue (pp. 154-217) est la double attention aux aspects morphologiques et syntaxiques des phénomènes étudiés; le lexique fait l'objet d'un paragraphe à part: ceci s'avère particulièrement opportun pour une langue où l'apport et l'influence du latin et / ou de l'italien sont souvent difficiles à discerner. Somme toute, selon M.G.-L. le français du traducteur anonyme est malgré tout moins hybride qu'on n'a pu le prétendre, compte tenu surtout de la proximité encore très marquée entre les trois langues à l'époque concernée.

4 La description du manuscrit et les principes d'édition sont présentés pp. 217-222; l'analyse de l'œuvre, nécessairement schématique, est organisée sur la base des huit livres de l'Ystoire (pp. 222-230).

5 L'édition du texte, très soignée, est divisée en livres et en paragraphes, et accompagnée d'un apparat critique en bas de page qui rend compte des interventions de l'éditrice et parfois les justifie; un seul regret: les notes au texte, riches et utiles, ne sont pas signalées dans l'édition, ce qui oblige le lecteur curieux, et certainement moins savant que M.G.-L., à des aller-retour parfois malcommodes.

6 Le glossaire tient compte des particularités linguistiques du texte, en signalant si nécessaire les mots latins ou italiens proches lorsque ceux-ci peuvent éclairer des formes ou des sens particuliers (pp. 597-642).

7 Index des noms de personnes et de peuples aux pp. 642-657, des toponymes aux pp. 659-668, bibliographie raisonnée aux pp. 669-684. Remarquons que la carte de l'Italie méridionale à la p. 685 ne saurait être utilisée qu'avec une (bonne) loupe.

8 L'Ystoire de li Normant est un récit riche en informations, certes, dont le but est de célébrer, dans une écriture proche de l'épopée, mais qui connait aussi les accents de l'hagiographie, les hauts faits des Normands occupant l'Italie du Sud: un texte intéressant pour les historiens de tout bord, historiens de l'Europe, de la littérature, de la langue (en particulier pour ceux qui s'intéressent à la diffusion de la langue française au Moyen Âge), qui tous reconnaîtront les grands mérites d'une édition à considérer comme absolument définitive. 